\title{
Three-Dimensional Reconstruction and Numerical Simulation Analysis of Acid-Corroded Sandstone Based on CT
}

\author{
Zizhen Miao, ${ }^{1}$ Shuguang Li $\mathbb{D},{ }^{1,2}$ Jiangsheng Xie, ${ }^{2}$ Runke Huo $\left(\mathbb{D},{ }^{1}\right.$ Fan Ding, ${ }^{1}$ Hongtao Zhu, ${ }^{2}$ \\ Xingzhi Yang, ${ }^{2}$ and Xiaoke $\mathrm{Li}^{2}$ \\ ${ }^{1}$ School of Civil Engineering, Xi'an University of Architecture and Technology, Xi'an 710055, China \\ ${ }^{2}$ Post-Doctoral Research Workstation, China Railway 20th Bureau Group Co. Ltd., Xi'an 710016, China \\ Correspondence should be addressed to Shuguang Li; 1ssgg2015@163.com
}

Received 25 January 2021; Revised 7 March 2021; Accepted 15 March 2021; Published 24 March 2021

Academic Editor: Yuantian Sun

Copyright (C) 2021 Zizhen Miao et al. This is an open access article distributed under the Creative Commons Attribution License, which permits unrestricted use, distribution, and reproduction in any medium, provided the original work is properly cited.

\begin{abstract}
Due to its unique technological characteristics, coal mining and production often encounter an acid corrosion environment caused by acid gases. Acid erosion and a series of chemical reactions caused by it often led to the deterioration of coal, rock, support structure, etc. and induced serious safety accidents. To further explore the macro-mesoscopic damage evolution law and failure mechanisms of rock masses under corrosion conditions through numerical simulation, a zonal refined numerical model that can reflect the acid corrosion characteristics of sandstone is established based on CT and digital image processing (DIP). The uniaxial compression test of corroded sandstone is simulated by ABAQUS software. Comparing the numerical simulation results with the physical experiment results, we found that the three-dimensional finite element model based on CT scanning technology can genuinely reflect sandstone's corrosion characteristic. The numerical simulation results of the stress-strain curve and macroscopic failure mode of the acid-corroded sandstone are in good agreement with the experimental results, which provides a useful method for further studying the damage evolution mechanism of the acid-corroded rock mass. Furthermore, the deformation and damage evolution law of the corroded sandstone under uniaxial compression is qualitatively analyzed based on the numerical simulation. The results show that the rock sample's axial displacement decreases gradually from top to bottom under the axial load, and the vertical variation is relatively uniform. In contrast, the rock sample's removal gradually increases with the increase of axial pressure, and the growth presents a certain degree of nonuniformity in the vertical. The acid-etched rock sample's damage starts from both the end and the middle; it first appears in the corroded area. Moreover, with the displacement load increase, it gradually develops and is merged in the middle of the rock sample and forms macroscopic damage.
\end{abstract}

\section{Introduction}

With the development of the economy, the scale of engineering construction such as deep earth resource exploitation, railway tunnel infrastructure construction, and urban underground space development continues to increase worldwide. The safety problems caused by the corresponding complex engineering-geological environment have become increasingly prominent [1-5]. Due to their unique technological characteristics, coal mining and production often encounter an acid corrosion environment caused by acid gases. Acid erosion and a series of chemical reactions caused by it often led to the deterioration of coal, rock, support structure, etc. and induced serious safety accidents [6-11]. Therefore, the research on the mechanical properties and failure mechanism of coal, rock, and structure under acid corrosion conditions has been widely concerned by scholars [7-24].

In studying the influence of acidic environment on rock materials' mechanical properties, scholars at home and abroad have made many explorations and achieved many results. In the early days, Feucht and Logan [15] studied the influence of different chemical solutions such as $\mathrm{CaCl}_{2}$, $\mathrm{NaCl}$, and $\mathrm{HCl}$ on sandstone's mechanical properties through triaxial compression tests and analyzed the microscopic characteristics of sandstone surface under 
chemical corrosion based on SEM. Hutchinson et al. [16] combined chemical experiments and SEM to study degradation laws of different forms of acidic substances on rock masses and discussed and established a corrosion theory based on chemical formulas and dissolution principles. Based on laboratory and field tests, Jiang et al. [7] and Sracek et al. [17] studied the macromechanical damage effects of the slope rock mass corroded by acid mine drainage (AMD). Taking calcareous sandstone and limestone as the objects, Han et al. [18] and Wang et al. [19] discussed the chemical corrosion mechanism from hydrochemistry through the erosion tests of different hydrochemical solutions. They illustrated the relationship between microstructure change and macromechanical properties of rock mass based on the porosity change and energy conversion. Feng et al. [20] applied the CT real-time scanning technology to study the mesomechanism of the sandstone's failure under triaxial compression and chemical erosion and established the corresponding damage variable model. Huo et al. [21, 22] and Li et al. [23, 24] analyzed the effects of different acidic environments (acid solution composition, $\mathrm{pH}$, temperature, and pressure) on the physical and mechanical properties of sandstone through laboratory acid corrosion tests. They deduced the damage variables of acid-corroded sandstone based on CT numbers and established the acid-corroded sandstone's statistical damage constitutive model.

The current research on the mechanical properties of rock under acid corrosion is mainly concentrated on laboratory macro-mesoscopic tests and theoretical model derivation. However, there has been little discussion about numerical simulation. The experimental instruments and technical means mostly limit the overall research. Therefore, it is necessary to explore a refined numerical model that can accurately reflect rock mass internal structure changes under acidic corrosion and further reveal the macro-mesoscopic damage evolution laws and failure mechanisms of rock masses under corrosive conditions through the corresponding numerical experiments.

As a nondestructive scanning technology, CT can perform high-resolution imaging of the sample without destroying the sample structure, providing a powerful means for reconstructing the three-dimensional numerical model that can truly reflect the internal structure of the sample. Wang et al. [25], Yang et al. [26], Wang et al. [27], Du et al. [28], Chen et al. [29], Sun et al. [30], and Obara et al. [31] used CT scanning technology to reconstruct the three-dimensional microstructure of coal, coal-rock, rock mass, concrete, and other materials. They conducted the corresponding numerical simulation studies to verify the CT three-dimensional reconstruction numerical simulation technology's effectiveness in describing structural damage evolution and fracture characteristics.

Therefore, in this paper, a partitioned finite element model that can reflect the acid corrosion characteristics of sandstone is established based on CT and DIP. The uniaxial compression test of corroded sandstone is simulated by ABAQUS software. Moreover, the accuracy of numerical simulation is verified by comparing it with the experimental data. Finally, the deformation and damage evolution law of the corroded sandstone during uniaxial compression were studied based on the numerical simulation.

\section{Experiment}

2.1. Rock Sample Preparation. The rock samples were taken from hydraulic engineering in Shaanxi Province and identified by X-ray diffraction experiment as cinereous finegrained calcareous lithic arkose. The samples are mainly greyish white in appearance with few nodules, there are fewer yellow-brown and grey-brown interlayers in some rock samples, and $0.3 \sim 1 \mathrm{~mm}$ pores exist in some rock layers. To ensure the unity of mineral composition and structure of rock samples, the strata of rock samples are distributed horizontally. All samples are taken from the same rock mass. According to the requirements of Standard for Test Methods of Engineering Rock Mass, the rock sample is processed into a standard cylinder with a diameter of $50 \mathrm{~mm}$ and a height of $100 \mathrm{~mm}$, as shown in Figure 1. The allowable deviation of the height-diameter ratio, the nonparallelism of the two ends, and the verticality of the rock specimen's axis to the end face are less than $0.3 \mathrm{~mm}, 0.05 \mathrm{~mm}$, and $0.25^{\circ}$, respectively [32]. Before the test, the initial mass and wave velocity of rock samples were tested (Figure 2), and rock samples with large deviations in mass and wave velocity were removed. The range of rock mass for the test was $522.32 \sim 528.2 \mathrm{~g}$, and the wave velocity range was $2933 \sim 2965 \mathrm{~m} / \mathrm{s}$.

2.2. Laboratory Acid Corrosion Experiment. Considering the acidic environment's complexity, hydrochloric acid $(\mathrm{HCl})$, which has a noticeable corrosion effect [22], was selected to simulate the acidic environment. The same container was used to prepare the same volume of $\mathrm{pH}=1 \mathrm{HCl}$ solution under room temperature and airtight conditions. The prepared standard rock samples were immersed in the above acidic solution for corrosion test. The experiment was divided into six stages $(180 \mathrm{~d})$, every 30 days for one step. To obtain a good corrosion effect in a relatively short time, the saturated solution was renewed every 30 days during the test (the type and $\mathrm{pH}$ of the replacement solution were unchanged). The soaking container is made of a ground glass beaker and sealed tightly to prevent dust, carbon dioxide, and other impurities from entering.

2.3. Uniaxial Compression and CT Scanning Experiment. When the soaking time reached 30, 90, and 180 days, the samples were taken out for the uniaxial compression test, and the CT scanning test was carried out on the marked rock samples.

The uniaxial compression test was completed in the MTS laboratory of Xi'an University of Science and Technology. The static loading rate of $0.05 \mathrm{~mm} / \mathrm{s}$ was used to carry out the uniaxial compressive strength test. The uniaxial compressive strength of sandstone corroded by acid solution in different periods was measured. The phenomena in the test process were recorded in detail, and the test data were analyzed. The uniaxial compressive stress-strain curve of rock samples was obtained. 


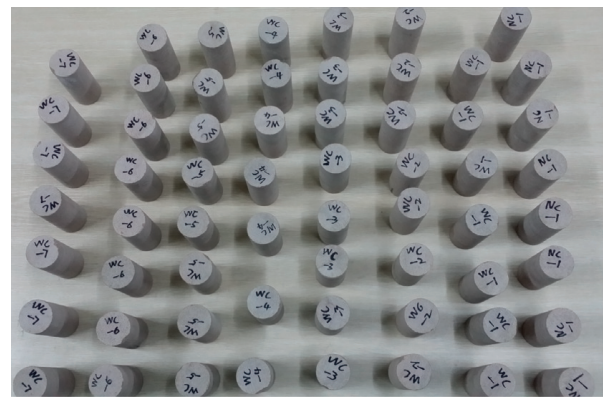

Figure 1: Standard rock samples for test.

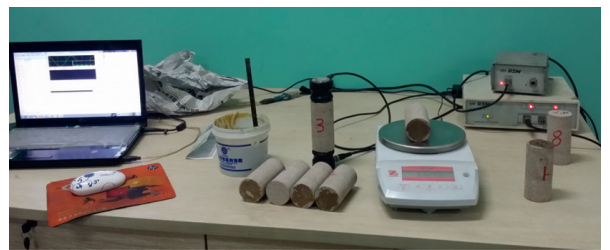

FIGURE 2: Weighing and acoustic testing of rock samples.

Philips Brilliance 16 spiral CT machine from Cold and Arid Regions Environmental and Engineering Research Institute, Chinese Academy of Sciences (CAS), was used for CT scanning test, which is composed of the detector, X-ray source, rock sample placement platform, data acquisition, image processing system, etc. The corresponding working principle is shown in Figure 3. Before the CT scanning test, the rock sample is placed on the sample placement platform. The X-ray source rotates $360^{\circ}$ around the rock sample at a specific set speed, and the rock sample placement platform can also move along a specific track at a certain set speed. The X-ray detector receives the X-ray emitted X-ray source after penetrating the rock sample and images the rock sample after computer calculation and transformation. $t$, the axial scanning layer thickness of the rock samples, is $3 \mathrm{~mm}$. Each rock sample can obtain 40 scan slices in DICOM format with a reconstruction matrix of $1024 \times 1024$, of which 33 CT images are valid. The final effective CT image voxel is $0.068 \times 0.068 \times 3 \mathrm{~mm}^{3}$, and the number of pixels after clipping is $735 \times 735=540,225$. For example, the CT image of the middle layer (the 16th layer) of the rock sample after the action of the $\mathrm{HCl}$ solution for different periods is shown in Figure 4.

\section{Reconstruction of Three-Dimensional Mesomodel of the Acid-Corroded Sandstone Based on CT Image}

3.1. CT Image Processing. It is necessary to process the original CT images effectively. Therefore, Image J software is applied to cut the cross-sectional CT images of the rock sample. The information that has nothing to do with the rock sample is removed to reduce the image memory and improve the calculation efficiency. Based on $\mathrm{C}++$ programming, the artifact information in the CT image is corrected to eliminate the abnormal appearance unrelated to the rock sample and ensure that it can genuinely reflect the mesostructure and composition of the cross-section of the acidetched rock sample. Finally, through Image J software, the preprocessing operations such as contrast enhancement, filtering, and denoising are carried out to achieve the image's best visualization effect for the following analysis and observation. The corresponding processing processes and outcomes are shown in Figure 5.

\subsection{Three-Dimensional Mesoscopic Model Construction.} The digital image is composed of a series of square pixels, and the square grid is used to characterize the two-dimensional structure of the material. The cube grid can establish the three-dimensional structure of the material [29-31]. Heterogeneous materials such as rock are all continuous solid materials. In the reconstruction process, it is assumed that the slice image can represent the microstructure of a material with a minimum thickness of $t$. If $t$ is extremely small, the error of the microstructure characterization can be ignored. Several slice images are arranged and superimposed in the depth direction according to the scanning order. Then, they can be converted into a three-dimensional cuboid grid that can represent the three-dimensional microstructure of the entire specimen. The image's information can be converted into the data required for modeling to establish the three-dimensional microstructure model of the material through the above vectorization method. In this study, the CT scanning layer thickness $t$ is $3 \mathrm{~mm}$, the pixel size is $0.068 \times 0.068 \mathrm{~mm}^{2}$, and correspondingly, the voxel size is $0.068 \times 0.068 \times 3 \mathrm{~mm}^{3}$. The three-dimensional vectorization principle is shown in Figure 6.

This paper uses MIMICS to construct the three-dimensional mesoscopic model of the acid-corroded sandstone. The specific process is as follows. First, the CT image after preprocessing is imported into MIMICS. The boundary threshold is selected, and the sandstone tissues in the 


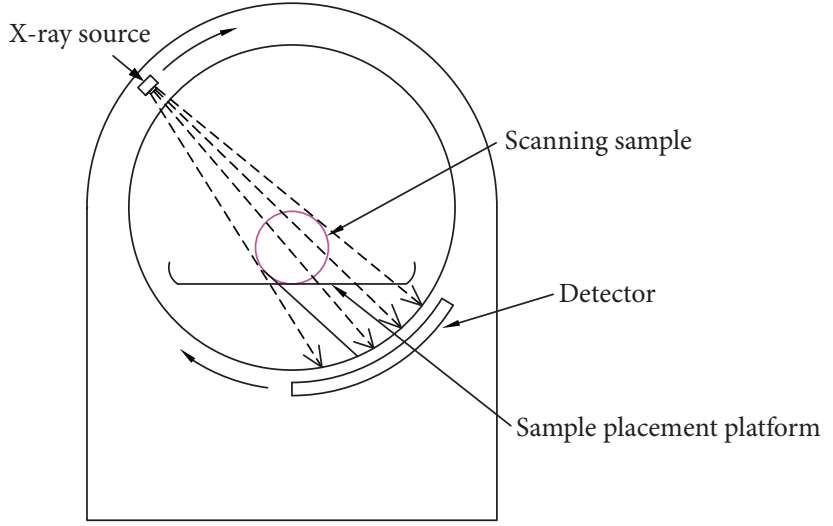

(a)

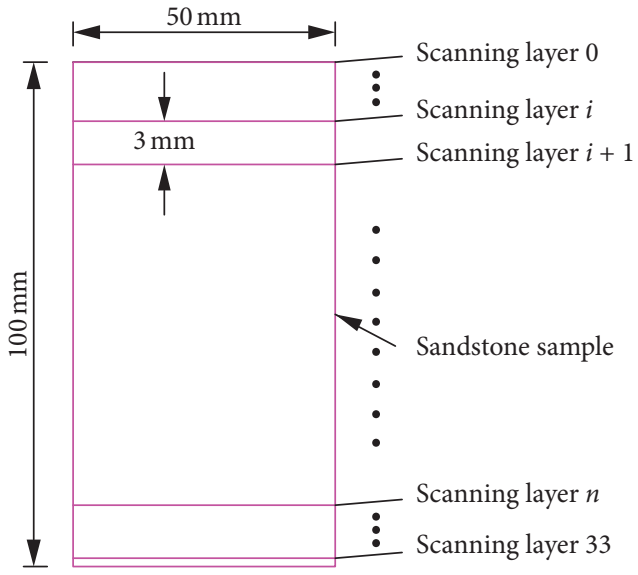

(b)

Figure 3: CT scanning schematic diagram of the rock sample. (a) The scanning principle of Philips Brilliance 16 spiral CT. (b) Layered scanning schematic diagram of the rock sample.

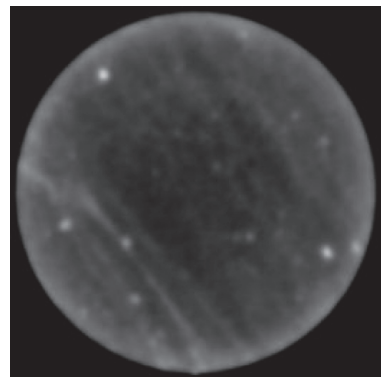

(a)

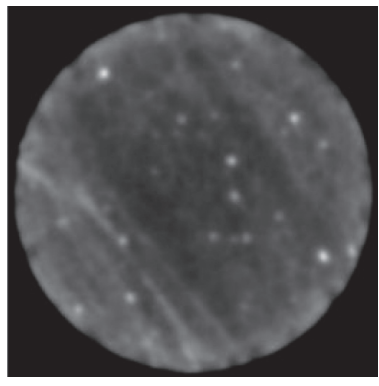

(b)

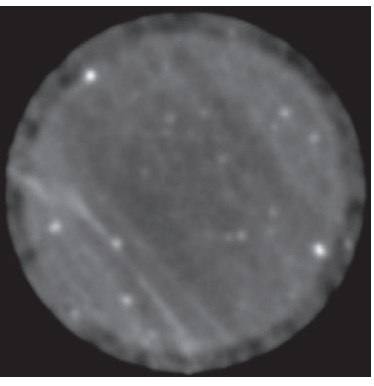

(c)

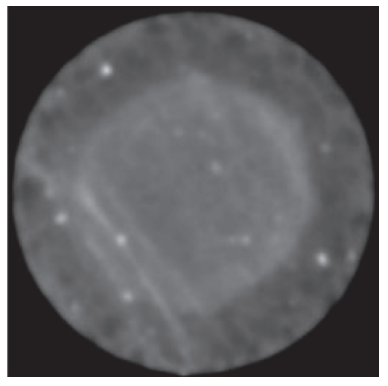

(d)

Figure 4: CT scanning image of the middle layer of rock sample after different corrosion times. (a) $\mathrm{pH}=1 \mathrm{HCl}(0 \mathrm{~d})$. (b) $\mathrm{pH}=1 \mathrm{HCl}(30 \mathrm{~d})$. (c) $\mathrm{pH}=1 \mathrm{HCl}(90 \mathrm{~d})$. (d) $\mathrm{pH}=1 \mathrm{HCl}(180 \mathrm{~d})$.

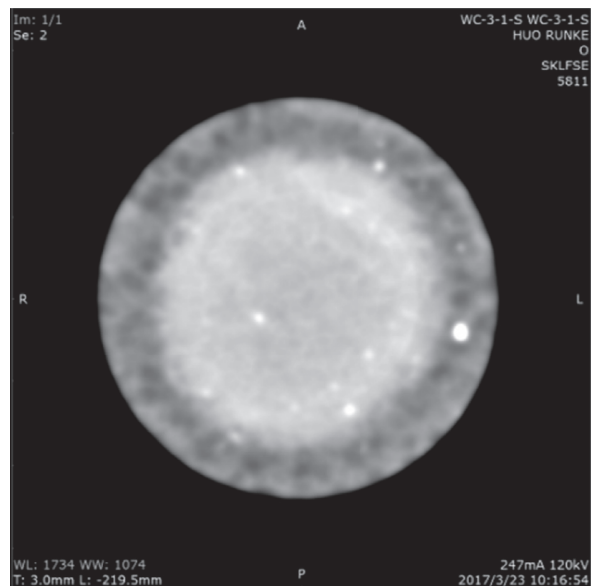

(a)

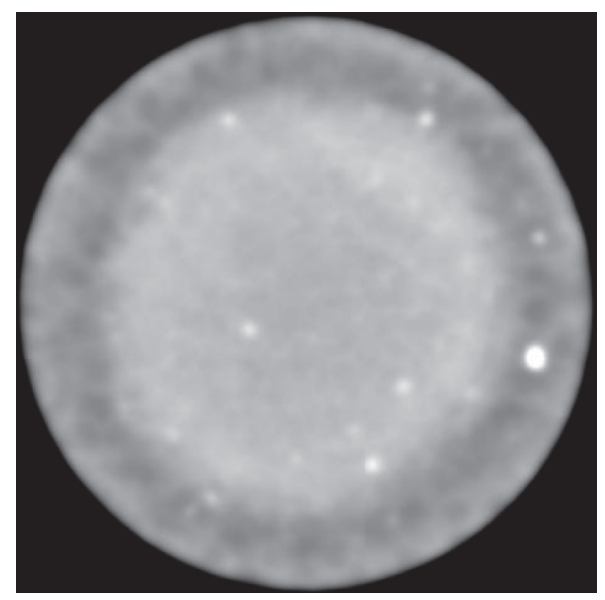

(b)

FIGURE 5: Continued. 


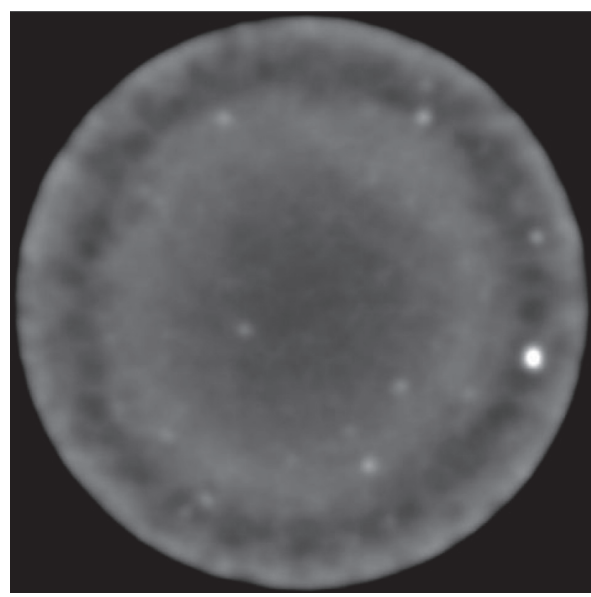

(c)

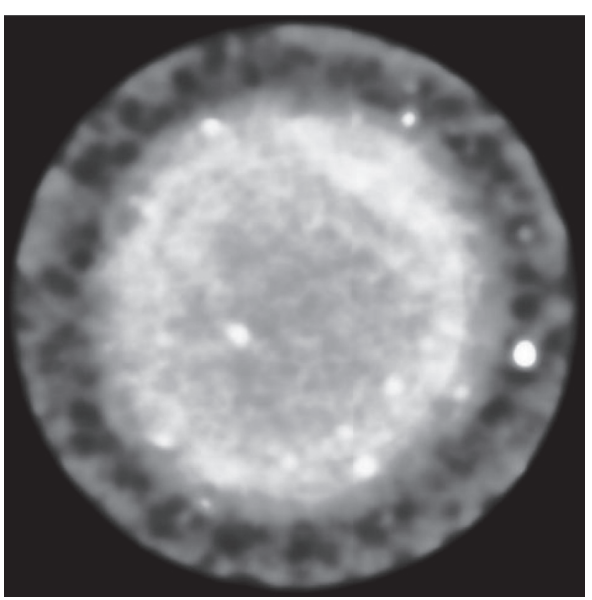

(d)

FIgURE 5: Two-dimensional CT image processing of acid-corroded sandstone. (a) Initial CT image in DICOM format. (b) Image cropping. (c) Image artifact reduction. (d) Image preprocessing.
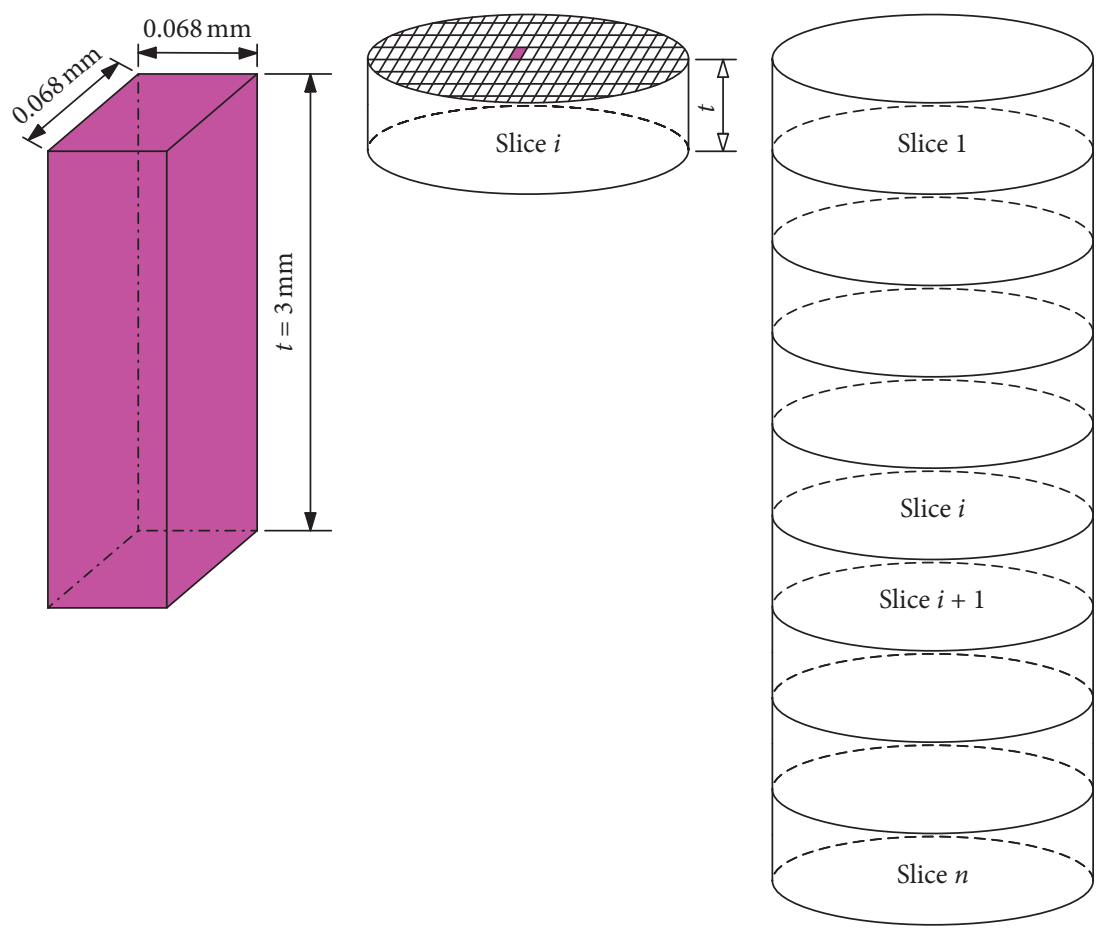

(a)

(b)

(c)

Figure 6: Schematic diagram of three-dimensional vectorization of microscopic images of rock samples. (a) The voxel unit. (b) The aggregate of single-layer voxel unit. (c) The whole rock sample.

corroded area and uncorroded areas are extracted. Subsequently, the extracted tissues are stored in different Masks. It is improved by image repair methods such as Region growing, Cavity fill, and Edit mask to remove redundant data, obtain high-quality segmented images, and enhance the subsequent model's discrimination and accuracy. Finally, the three-dimensional reconstruction model can be obtained by vectorizing and superimposing the segmented two-dimensional CT image, as shown in Figures 7 and 8.

\section{Verification and Analysis of Numerical Simulation}

4.1. Establishment of Finite Element Model. Meshing the geometric model of materials to establish the finite element model is essential before the finite element calculation. The paper uses Hypermesh to divide, inspect, and optimize the model mesh. The corresponding steps are as follows. First, the sandstone model reconstructed in MIMICS is exported 


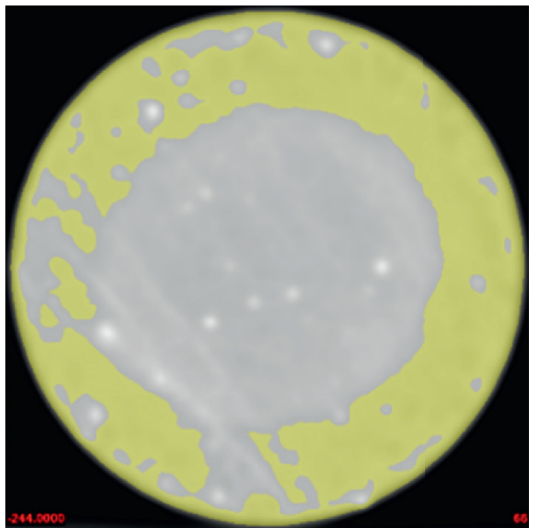

(a)

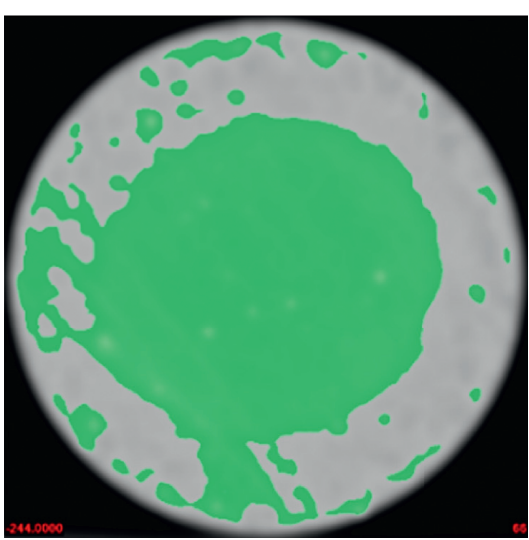

(b)

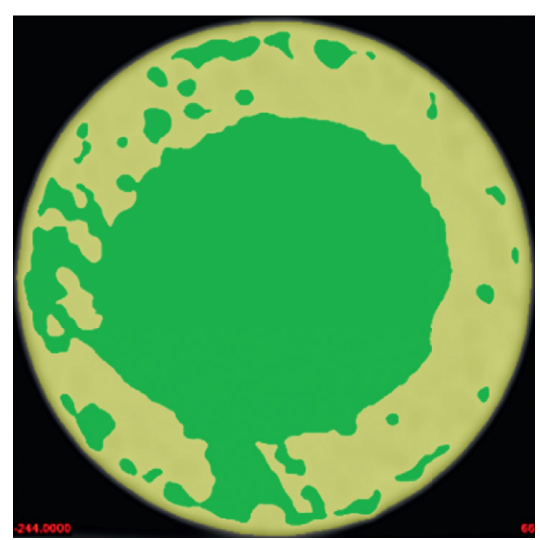

(c)

FIgURE 7: Two-dimensional CT image of the acid-corroded sandstone after segmentation. (a) Corroded area selection. (b) Uncorroded area selection. (c) Rock sample slice as a whole.

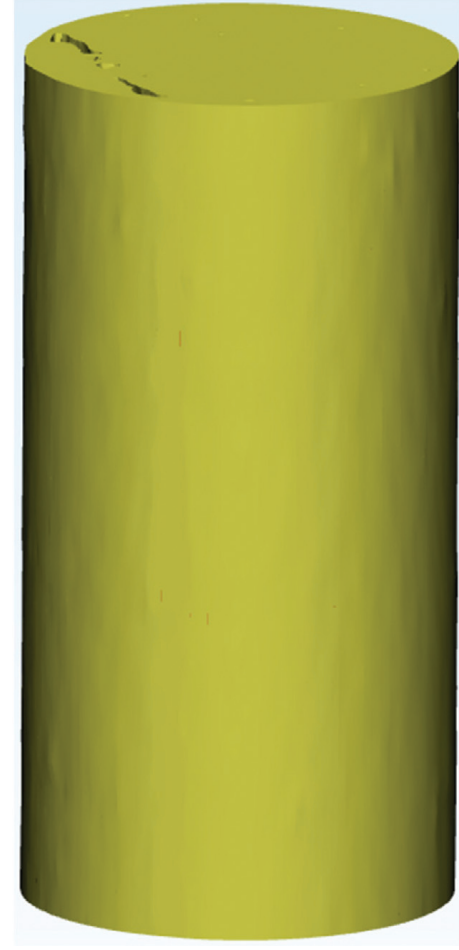

(a)

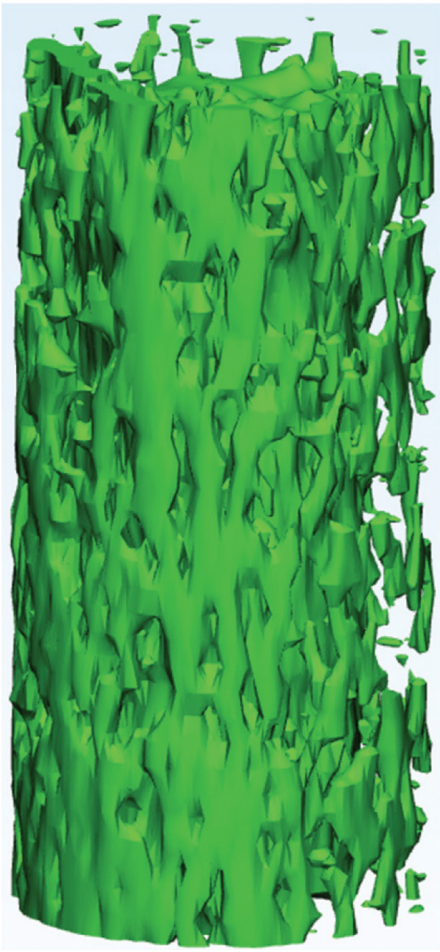

(b)

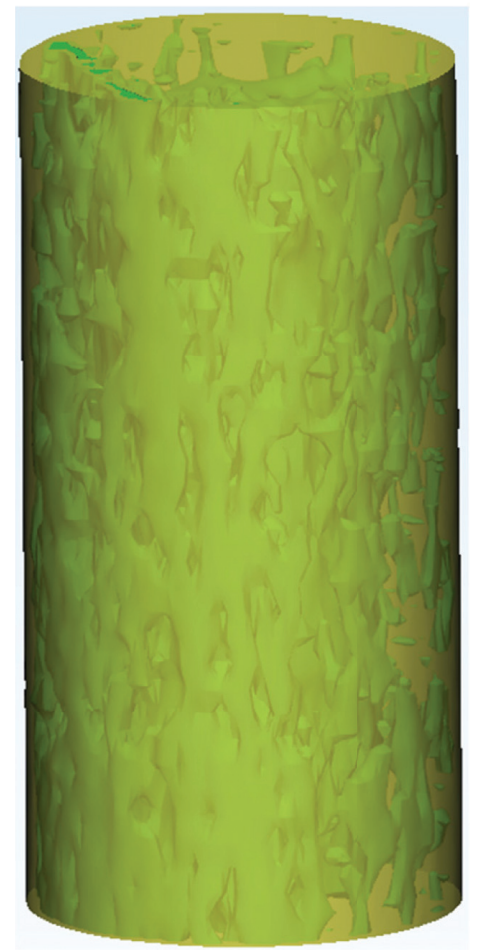

(c)

Figure 8: Three-dimensional mesoscopic model of the acid-corroded sandstone. (a) Corroded area. (b) Uncorroded area. (c) Rock sample as a whole.

in the form of an STL file. Then, the STL file is imported into Hypermesh. The warpage, aspect ratio, ratio of the maximum angle to the minimum angle, and broken elements of the mesh elements are inspected and repaired in 2D. Subsequently, the volume mesh model is generated. The warpage, squareness, and tetrahedral element collapse index of the model elements are inspected and repaired in 3D. After the mesh element inspection and repair are completed, save the model in the required format.
This paper selects the data of the sandstone corroded by $\mathrm{pH}=1 \mathrm{HCl}$ for 90 days for simulation analysis. The model element adopts the modified quadratic triangle and tetrahedron element C3D10M. The three-dimensional mesh model of the acid-corroded sandstone repaired by Hypermesh for finite element calculation and analysis is shown in Figures 9 and 10. The entire model is divided into 185,211 parts, including 88,801 corroded areas and 96,410 uncorroded areas. 


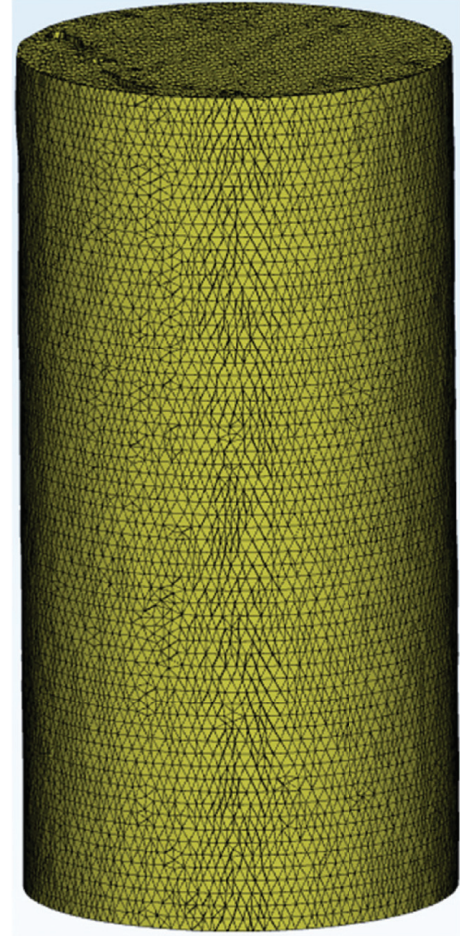

(a)

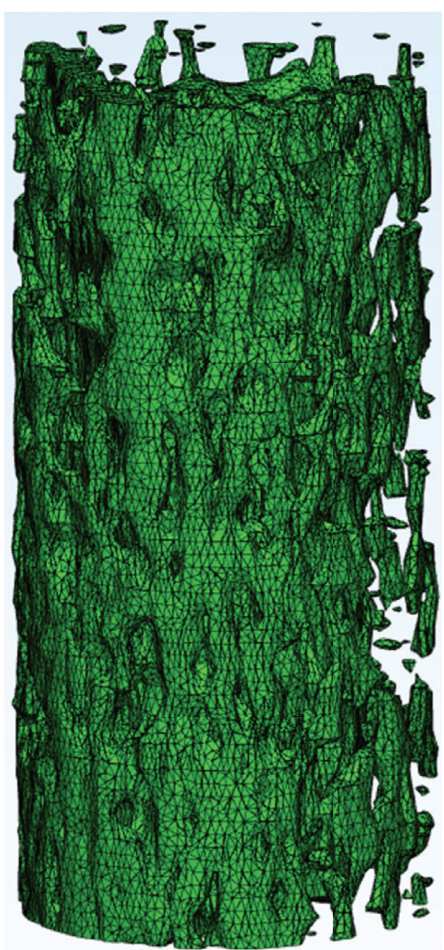

(b)

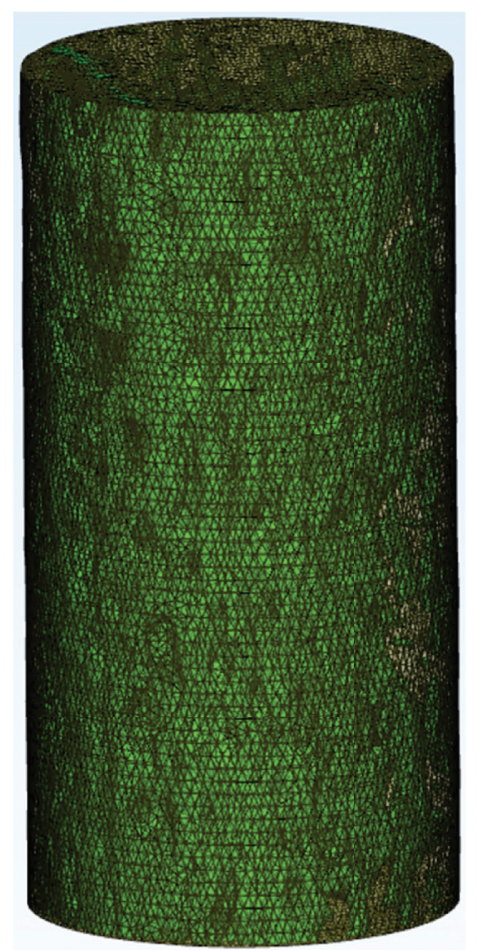

(c)

FIGURE 9: Finite element mesh model of acid-corroded sandstone. (a) Corrosion zone. (b) Uncorroded zone. (c) Rock sample as a whole.

4.2. Selection of Constitutive Model and Parameters. The damage plasticity model of concrete in ABAQUS adopts isotropic elastic damage combined with isotropic tensile and compressive plasticity theory to characterize the inelastic behavior of quasibrittle materials. It can accurately simulate the mechanical behavior of quasibrittle materials such as rock, concrete, gypsum, ceramics, and glass under monotonic and cyclic loading [33-37]. Therefore, this paper chooses it as the constitutive model of acid-corroded sandstone.

The flow potential in the model is calculated according to the parabolic function model proposed by Drucker Prager. The flow potential function in the damage plastic model used in this paper is shown in equation (1). In the equation, $\psi$ is the dilation angle in the $p-q$ plane of the rock sample. It can be obtained from the high confining pressure biaxial compression test; $\varepsilon$ is the plastic potential equation's flow eccentricity parameter; usually take 0.1 .

$$
G(\sigma)=\sqrt{\left(\varepsilon \sigma_{\mathrm{to}} \tan \psi\right)^{2}+\bar{q}^{2}}-\bar{p} \tan \psi .
$$

According to the research results of Lee and Fenves [37], the modified yield surface function of the model is formulated by equations $(2) \sim(5)$ :

$$
\begin{gathered}
F=\frac{1}{1-\alpha}\left(\sqrt{2 \mathbf{J}_{2}}+\alpha \mathbf{I}_{1}+\beta \sigma_{\max }+\gamma \sigma_{\max }\right)-\sigma_{c 0} \\
\alpha=\frac{\sigma_{b 0} / \sigma_{c 0}-1}{2 \sigma_{b 0} / \sigma_{c 0}-1},
\end{gathered}
$$

$$
\begin{gathered}
\beta=\frac{\sigma_{c 0}}{\sigma_{t 0}}(1-\alpha)-(1+\alpha), \\
\gamma=\frac{3(1-K)}{2 K-1} .
\end{gathered}
$$

In the formula, $\sigma_{b 0} / \sigma_{c 0}$ is biaxial compressive strength to uniaxial compressive strength of the material, which can be measured by test; and $K$ is the ratio of tensile meridian to compressive meridian constant stress, which is used to define the projection shape of the yield surface in the deviatoric plane, as shown in Figure 11, $K_{c}=1$ under Drucker-Prager yield criterion, $K_{c}=2 / 3$ under Rankine formula, this simulation adopts $2 / 3$ suggested by Lubliner et.al. [38].

The viscosity coefficient $(\mu)$ has little influence on the calculation result, but it can improve the numerical calculation's stability and convergence. By comparison of numerical simulation, 0.005 is chosen.

In conclusion, based on the uniaxial compression test data [22] and the suggestions of related literature [34-40], and through numerical simulation optimization, the model parameters of sandstone in the corroded area and uncorroded area are determined as shown in Table 1.

4.3. Boundary Conditions and Loading Process. To truly simulate the uniaxial compression test conditions, steel plates (discrete rigid bodies) are set at both ends of the rock sample, and a reference point is created. The displacement of the steel plate at one end is constrained in $X, Y$, and $Z$ 


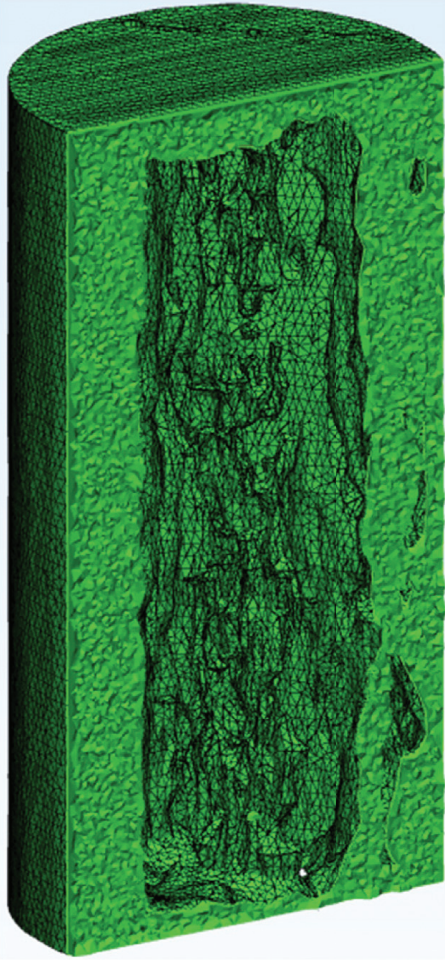

(a)

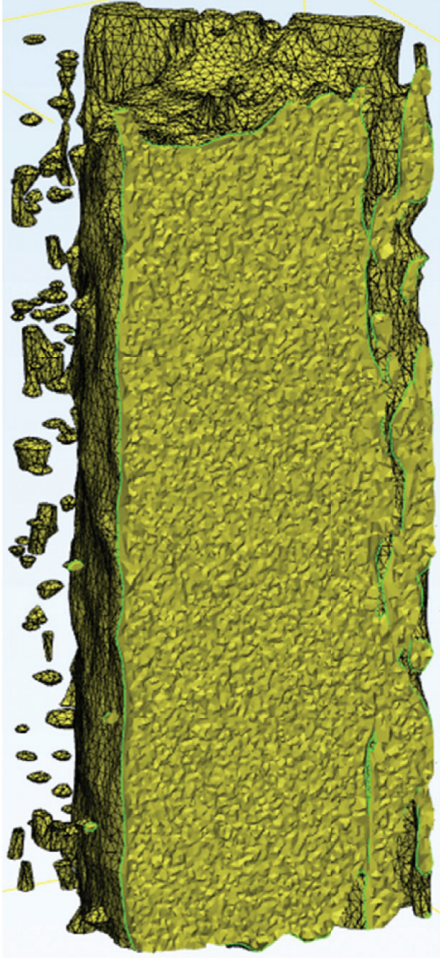

(b)

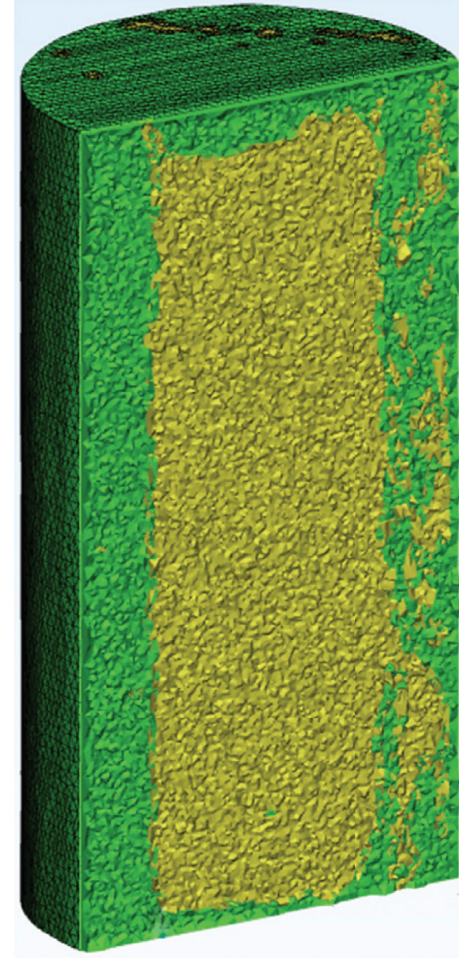

(c)

FIGURE 10: Profile of finite element mesh model of acid-corroded sandstone. (a) Corrosion zone. (b) Uncorroded zone. (c) Rock sample as a whole.

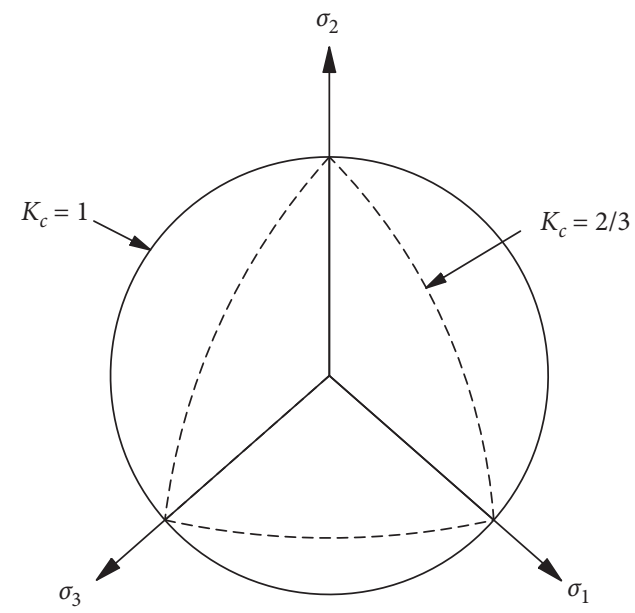

Figure 11: Projection of yield surface on the deviatoric plane.

TABLE 1: Numerical model parameters.

\begin{tabular}{lcccccccc}
\hline $\begin{array}{l}\text { Division of } \\
\text { sandstone }\end{array}$ & $\begin{array}{c}\text { Density } \\
\left(\mathrm{g} / \mathrm{cm}^{3}\right)\end{array}$ & $\begin{array}{c}\text { Young's modulus } \\
(\mathrm{MPa})\end{array}$ & $\begin{array}{c}\text { Poisson's } \\
\text { ratio }\end{array}$ & $\begin{array}{c}\text { Dilation angle } \\
\left(^{\circ}\right)\end{array}$ & $\begin{array}{c}\text { Eccentricity } \\
\sigma_{b 0} / \sigma_{c 0}\end{array}$ & $\begin{array}{c}K \\
\text { parameters }\end{array}$ \\
\hline $\begin{array}{l}\text { Corrosion zone } \\
\text { Uncorroded zone }\end{array}$ & 2.7 & 1983 & 0.200 & 25 & 0.1 & 0.9 & 0.667 & 0.005 \\
\end{tabular}




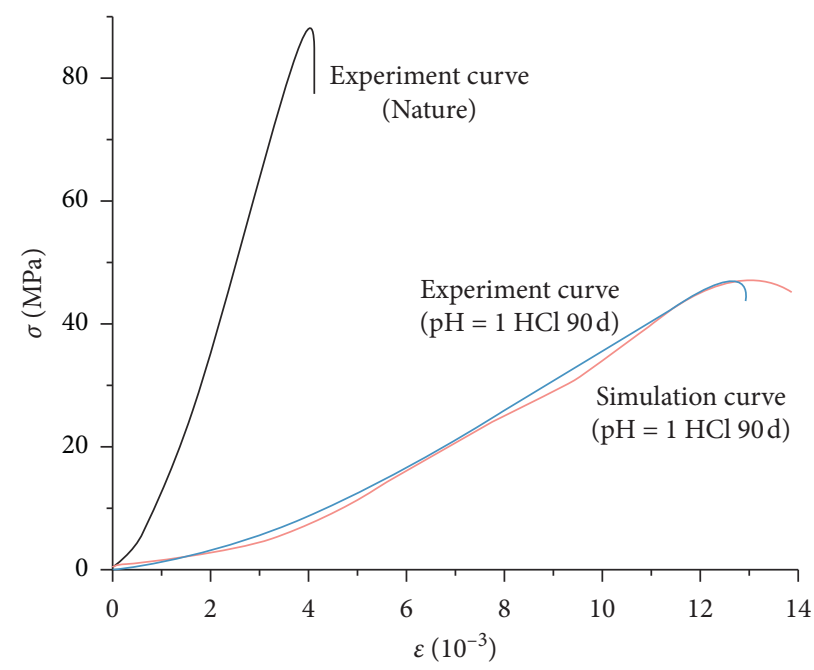

FigURE 12: Uniaxial compression stress-strain curves of rock samples subjected to acid corrosion for 90 days.

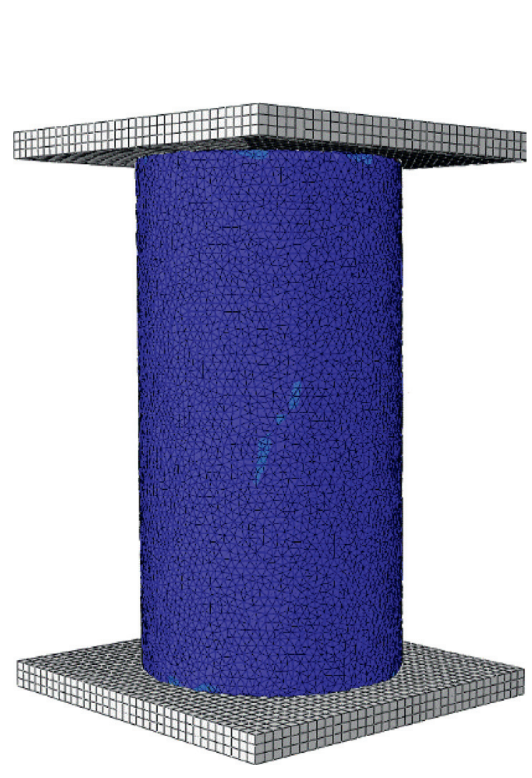

(a)
PE, max, principal (Avg: $75 \%)$

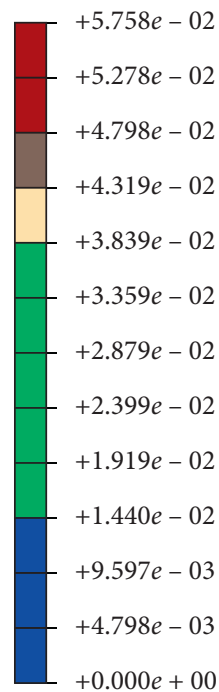

PE, max, principal (Avg: $75 \%)$

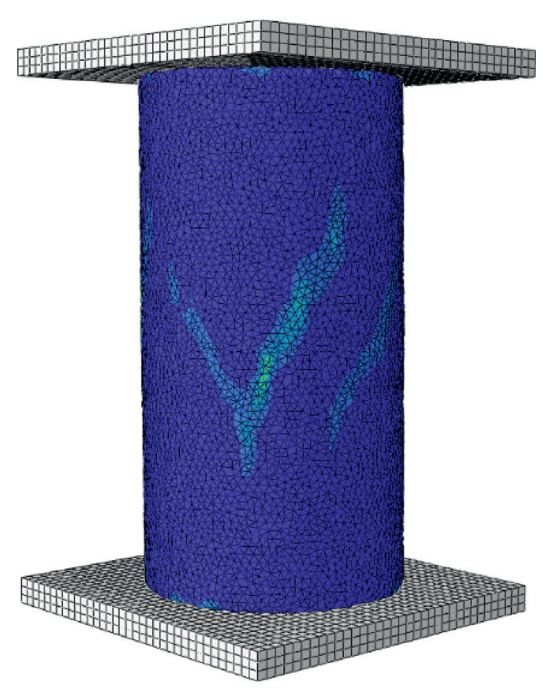

(b)

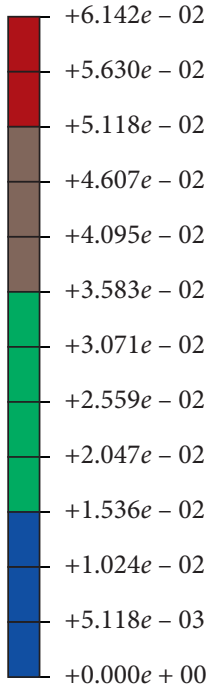

$+0.000 e+00$

Figure 13: Continued. 
PE, max, principal (Avg: $75 \%)$

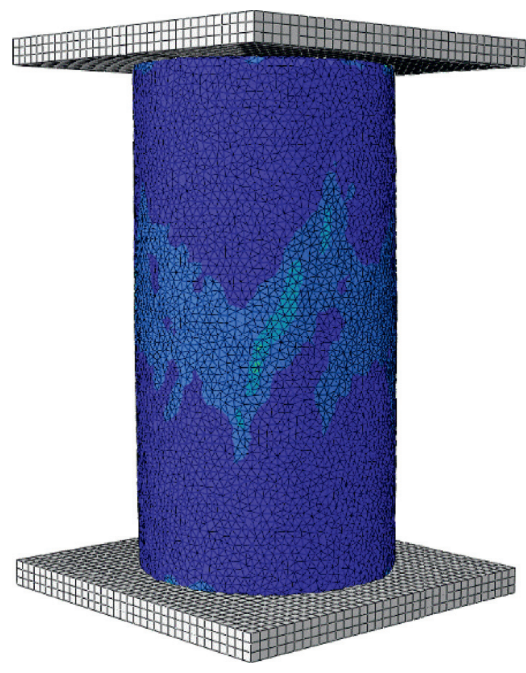

(c)

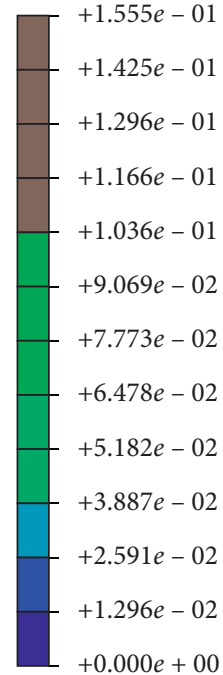

$+0.000 e+00$

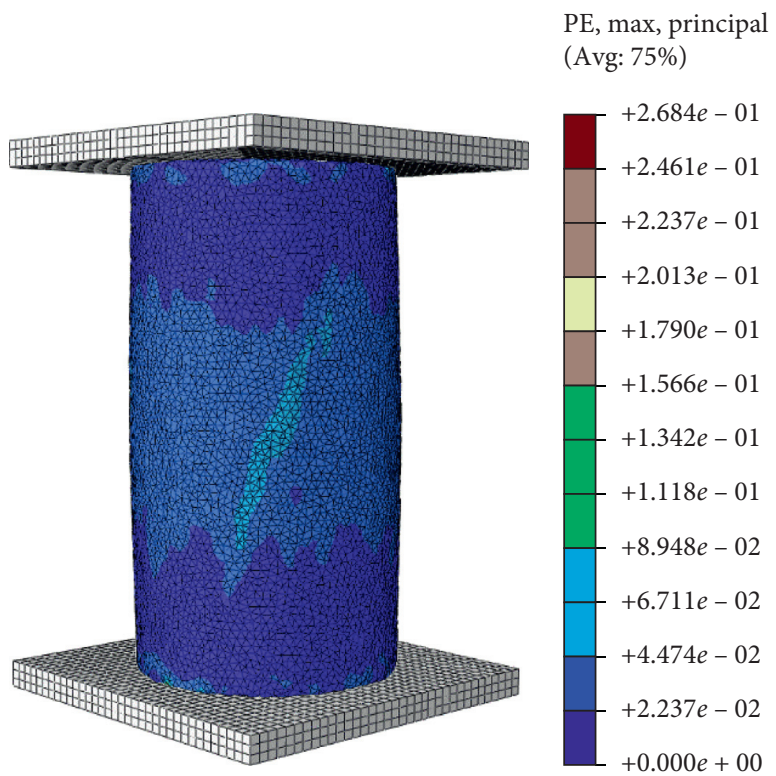

(d)

FIgURE 13: Equivalent plastic strain nephogram. (a) The initial stage of compression. (b) The middle stage of compression. (c) The later stage of compression. (d) Failure stage.

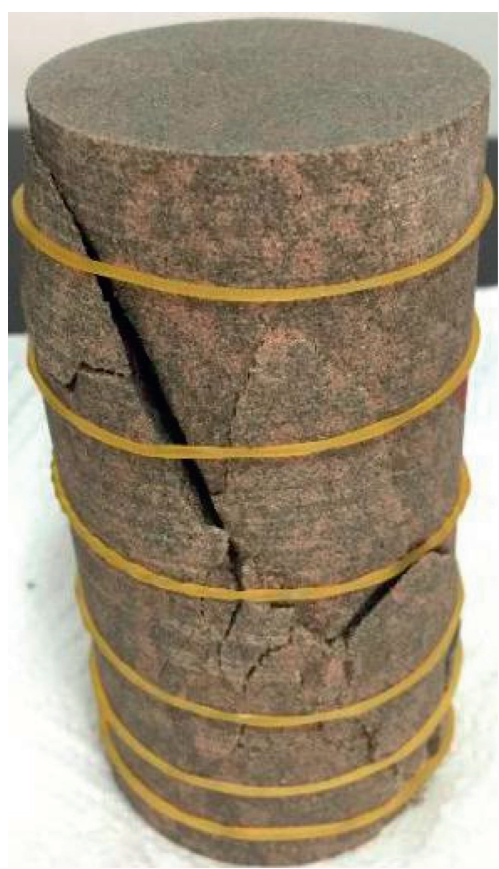

(a)

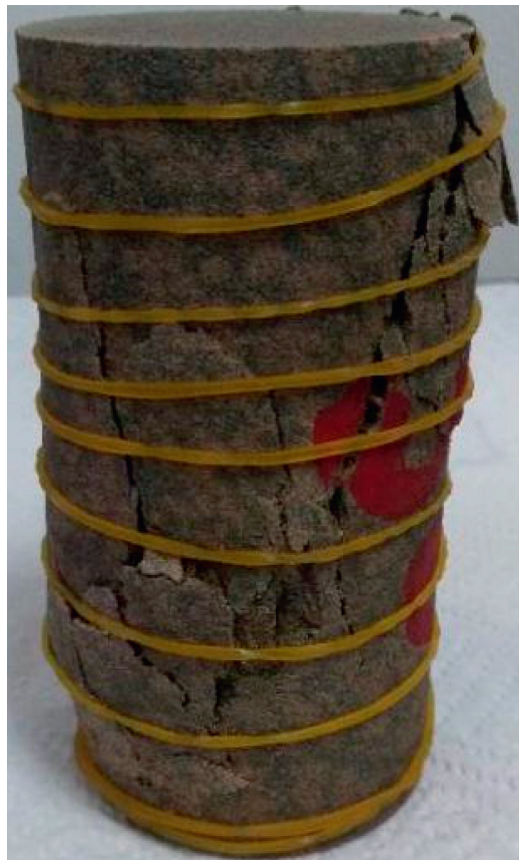

(b)

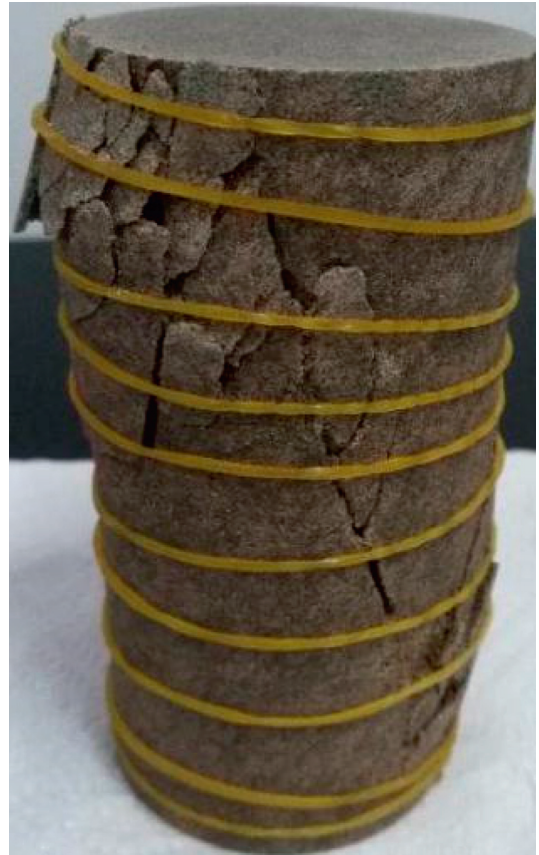

(c)

Figure 14: Macroscopic failure morphology of rock samples subjected to $\mathrm{pH}=1 \mathrm{HCl}$ for 90 days.

directions, while the steel plate at the other end can move freely along the axial path of the rock sample. The loading rate is $0.002 \mathrm{~mm} / \mathrm{step}$ according to the displacement control method.
The TIE command is adopted to simulate the contact relationship between the discrete rigid body and the model to conform to the constraint effect of the laboratory loading test on the rock sample. After the loading and the boundary 


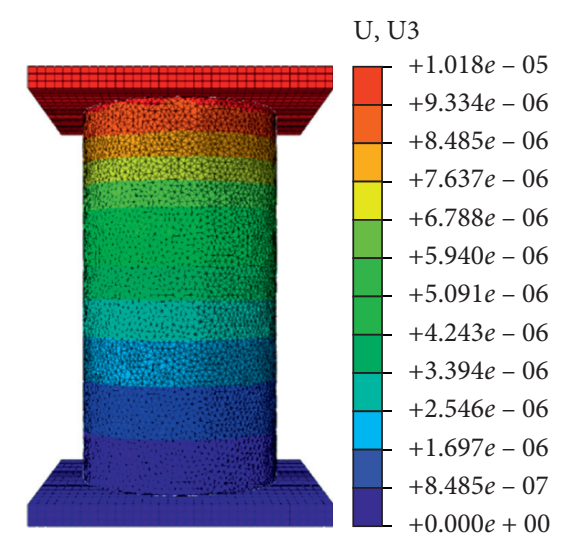

(a)

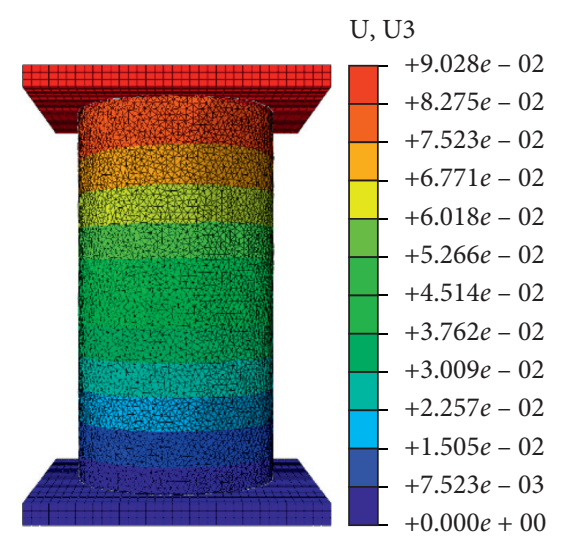

(b)

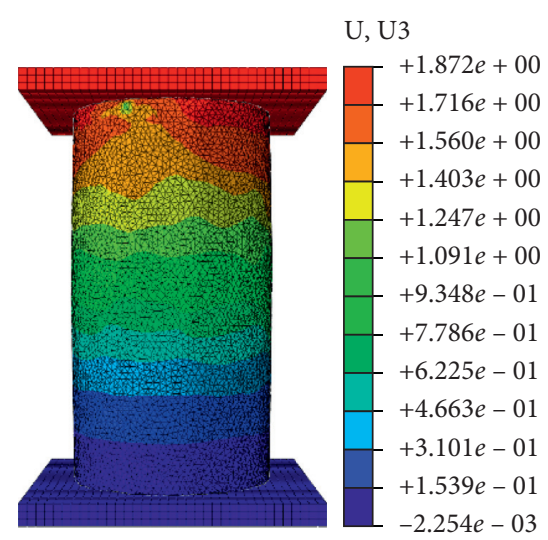

(c)

FIGURE 15: Vertical displacement nephogram of rock sample subjected to $\mathrm{pH}=1 \mathrm{HCl}$ for 90 days. (a) The initial stage of compression. (b) The middle stage of compression. (c) The later stage of compression.

constraint are set, the steel plate also is meshed, and then the analysis and corresponding solution calculation are carried out.

\subsection{Simulation Results and Analysis}

4.4.1. Simulation Effect Verification. To verify the simulation effect of the reconstructed model, the results of the numerical experiment and physical experiment were compared and analyzed from two aspects: stress-strain relationship and failure mode. The stress-strain curve obtained by physical experiment and numerical simulation is shown in Figure 12. It can be seen that, under acid corrosion conditions, the peak strength and elastic modulus of sandstone deteriorated and decreased, the peak strain increased, and the line shape of the compaction stage appeared concave. The rock sample showed specific softening characteristics [22]. The coincidence degree of the simulated curve and the experimental curve is high, and the peak strength error between the simulation and experiment is $0.7 \%$. The numerical simulation method based on a three-dimensional reconstruction model can better reflect the stress-strain relationship of acidcorroded sandstone.

The damage plasticity model in ABAQUS can reflect the occurrence and development direction of material cracks through the maximum principal plastic strain nephogram (equivalent plastic strain nephogram). That is to say, the normal vector of the crack surface is parallel to the direction of the maximum principal plastic strain and judges the crack development of the material. Figure 13 shows the equivalent plastic strain nephogram of the rock sample corroded by $\mathrm{pH}=1 \mathrm{HCl}$ solution for 90 days. It can be seen that, under the action of vertical load, the cracks mainly appear in the end and the middle of the rock sample. With the displacement load increase, the plastic zone gradually expands from the center and forms the main crack $45^{\circ}$ from the axial direction. The colour of the middle part of the rock sample and the significant damage in the nephogram gradually deepens, indicating that the crack gradually expands and coalesces.
Figure 14 shows the failure modes of the rock sample in the laboratory uniaxial compression experiment. Compared with Figure 13, it can be found that the simulation results are consistent with the results of the physical laboratory test. The macroscopic failure modes of the rock sample all start from its middle position, extend obliquely downward, gradually merge, and form visible failure. During the failure process, the cracks expanded, developed irregularly from the inside of the rock sample to the surroundings, and then formed multiple failure cracks on the surface of the rock sample, accompanied by different degrees of block dropping in the ends of the rock sample.

The simulation results of the acid-corroded sandstone model established in this paper are in good agreement with the physical experiment results from the above analysis. It is feasible to establish the corresponding numerical model based on CT images and study the mechanical behavior and fracture mechanism of acidcorroded rocks.

\subsubsection{Deformation and Damage Evolution Analysis Based on} Numerical Simulation. The feasibility of the model was verified by the comparison between the numerical simulation and physical experiment. Therefore, based on the established numerical model, the displacement and damage evolution law of acid corroded sandstone under uniaxial compression load are further analyzed. The corresponding results are shown in Figures 15 and 16. The figure shows that the rock sample's axial displacement decreases gradually from top to bottom under the axial load, and the vertical variation is relatively uniform. The maximum displacement appears at the top of the rock sample. With the increase of the load, the displacement of the rock sample rises gradually. Still, the increase presents a certain degree of nonuniformity in the vertical, and this nonuniformity becomes more evident with the rise of the load. The damage of the acid-etched rock sample mainly starts from the end and the middle. Moreover, with the displacement load increase, it gradually develops and coalesces in the middle of the rock sample and 


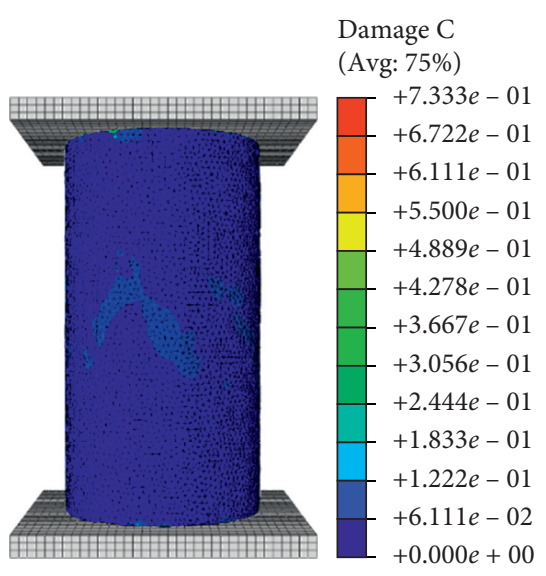

(a)

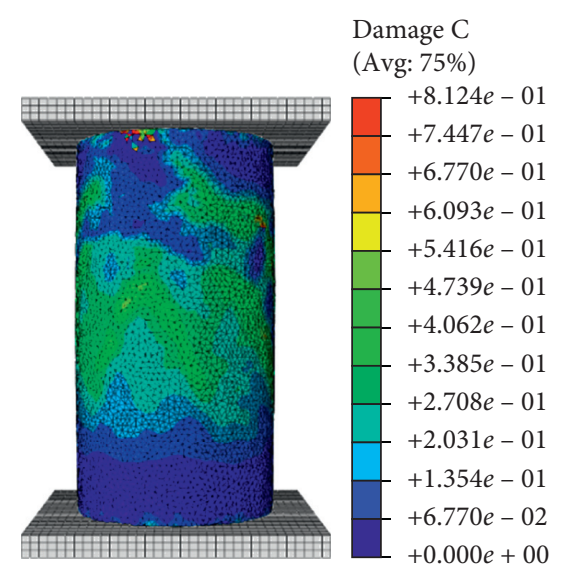

(b)

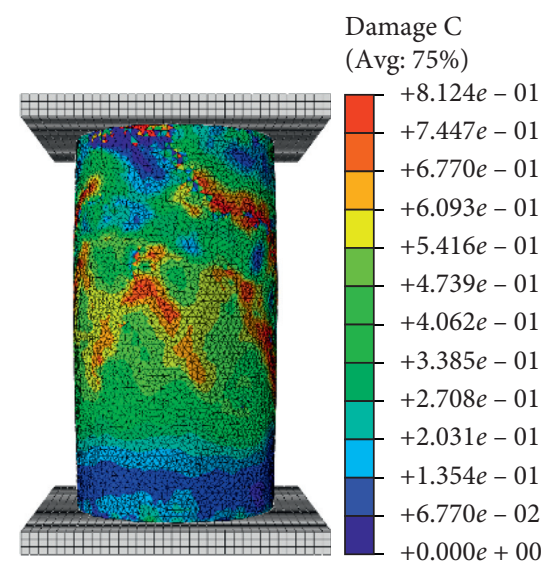

(c)

Figure 16: Compression damage nephogram of rock sample subjected to $\mathrm{pH}=1 \mathrm{HCl}$ for 90 days. (a) The initial stage of compression. (b) The middle stage of compression. (c) The later stage of compression.

forms macroscopic damage. By comparison, the rock sample's first damage areas are all in the outer corrosion area, mainly because there are many pores and microcracks in the corrosion area of the rock sample, which are relatively weak, so the damage occurs first. When the load is applied, due to the different elastic modulus and Poisson's ratio of the materials in the corroded and uncorroded areas of the rock sample, the transverse strains produced are also different. With the generation of tensile stress, when the tensile stress is greater than the bonding strength, the microcracks form and expand along the transition zone of adjacent interfaces and finally merge.

\section{Conclusion}

This paper uses CT scanning technology and digital image processing technology to identify and characterize the corrosion area of acid-corroded sandstone and the noncorrosion area. With the help of MIMICS and Hypermesh software, the three-dimensional digital model of the material is reconstructed. Then, the corroded sandstone's uniaxial compression experiment is simulated and analyzed based on the reconstructed model combined with ABAQUS software. The results were compared with the experimental laboratory results. The following conclusions can be made:

(1) Based on CT scanning technology and digital image processing technology, the acid-corroded sandstone's three-dimensional mesomodel can be reconstructed. Combined with the damage plastic constitutive model in ABAQUS, the reconstructed model can well realize the uniaxial compression experimental simulation and accurately reflect sandstone's corrosion characteristics. It provides a feasible method for further studying the mechanical behavior and damage evolution mechanism of rock corroded by acid.

(2) The numerical simulation results show that the rock sample's axial displacement decreases gradually from top to bottom under the axial load, and the vertical variation is relatively uniform. The maximum displacement appears at the top of the rock sample. With the increase of the load, the displacement of the rock sample rises gradually. Still, the increase presents a certain degree of nonuniformity in the vertical, and this nonuniformity becomes more evident with the rise of the load. The acid-etched rock sample's damage starts from both the end and the middle and first appears in the corroded area. Moreover, with the displacement load increase, it gradually develops and coalesces in the middle of the rock sample and forms macroscopic damage.

(3) Being limited to the length and experimental conditions, this paper mainly proposes and verifies CT scanning technology feasibility in three-dimensional reconstruction and numerical simulation of acideroded sandstone. We discussed the deformation and damage evolution laws of the corroded sandstone under uniaxial compression based on the numerical simulation. However, this study lacks an in-depth discussion of the acid-eroded rock masses' damage evolution characteristics under triaxial compression and during the corrosion process. In the follow-up study, the scanning system can be integrated with the corrosion process and loading process to simulate the damage evolution of rock mass under uniaxial and triaxial loads dynamically and in real-time.

\section{Data Availability}

The data included in this study are available from the corresponding author upon request.

\section{Conflicts of Interest}

The authors declare that there are no conflicts of interest regarding the publication of this paper. 


\section{Acknowledgments}

The authors would like to thank the China Post-Doctoral Science Foundation (2020M673525), the China Railway 20th Bureau Group Co. Ltd. (YF2000SD01A and YF1600SD03B), and the National Natural Science Foundation of China (42077274 and 41172237) for supporting this research project.

\section{References}

[1] X. He and L. Song, "Status and future tasks of coal mining safety in China," Safety Science, vol. 50, no. 4, pp. 894-898, 2012.

[2] K. Wu, Z. S. Shao, S. Qin, W. Wei, and Z. F. Chu, "A critical review on the performance of yielding supports in squeezing tunnels," Tunnelling and Underground Space Technology, vol. 114, no. 1, Article ID 103815, 2021.

[3] C. Gao, Z. Zhou, Z. Li, L. Li, and S. Cheng, "Peridynamics simulation of surrounding rock damage characteristics during tunnel excavation," Tunnelling and Underground Space Technology, vol. 97, Article ID 103289, 2020.

[4] Z. Chu, Z. Wu, Q. Liu, B. Liu, and J. Sun, "Analytical solution for lined circular tunnels in deep viscoelastic burgers rock considering the longitudinal discontinuous excavation and sequential installation of liners," Journal of Engineering $\mathrm{Me}$ chanics, vol. 147, no. 4, Article ID 04021009, 2021.

[5] K. Wu, Z. Shao, and S. Qin, "An analytical design method for ductile support structures in squeezing tunnels," Archives of Civil and Mechanical Engineering, vol. 20, no. 3, pp. 1-13, 2020.

[6] H. H. Chen, H. Y. Zhao, H. S. Shao, and S. Z. Zhao, "Corrosive wear behaviour of coal," Journal of China Coal Society, vol. 22, no. 6, pp. 84-88, 1997.

[7] L.-C. Jiang, J.-S. Chen, and A.-X. Wu, "Erosion characteristic of slope sandstone soaking in acid mine drainage," Journal of Central South University of Technology, vol. 14, no. 2, pp. 236-242, 2007.

[8] H.-L. Lv, Y. Ma, S.-C. Zhou, and K. Liu, "Case study on the deterioration and collapse mechanism and curing technique of RC coal bunkers," Procedia Earth and Planetary Science, vol. 1, no. 1, pp. 606-611, 2009.

[9] J. M. Davila, A. M. Sarmiento, J. C. Fortes et al., "Determination of the extreme reduction of concrete strength due to acid mine drainage by laboratory tests on specimens located in a real environment," Construction and Building Materials, vol. 269, Article ID 121817, 2021.

[10] Y. Peng and W. Timms, "Hydrogeochemical modelling of corrosive environment contributing to premature failure of anchor bolts in underground coal mines," Journal of Central South University, vol. 27, no. 5, pp. 1599-1610, 2020.

[11] E. Gamboa and A. Atrens, "Environmental influence on the stress corrosion cracking of rock bolts," Engineering Failure Analysis, vol. 10, no. 5, pp. 521-558, 2003.

[12] S. Li, G. Ni, H. Wang, M. Xun, and Y. Xu, "Effects of acid solution of different components on the pore structure and mechanical properties of coal," Advanced Powder Technology, vol. 31, no. 4, pp. 1736-1747, 2020.

[13] L. Yu, Z. Zhang, J. Wu, R. Liu, H. Qin, and P. Fan, "Experimental study on the dynamic fracture mechanical properties of limestone after chemical corrosion," Theoretical and Applied Fracture Mechanics, vol. 108, Article ID 102620, 2020 .
[14] A. Basu, B. K. Ram, N. K. Nanda, and S. S. Nayak, "Deterioration of shear strength parameters of limestone joints under simulated acid rain condition," International Journal of Rock Mechanics and Mining Sciences, vol. 135, Article ID 104508, 2020.

[15] L. J. Feucht and J. M. Logan, "Effects of chemically active solutions on shearing behavior of a sandstone," Tectonophysics, vol. 175, no. 1-3, pp. 159-176, 1990.

[16] A. J. Hutchinson, J. B. Johnson, G. E. Thompson, G. C. Wood, P. W. Sage, and M. J. Cooke, "Stone degradation due to wet deposition of pollutants," Corrosion Science, vol. 34, no. 11, pp. 1881-1898, 1993.

[17] O. Sracek, M. Choquette, P. Gelinas, R. Lefebvre, and R. V. Nicholson, "Geochemical characterization of acid mine drainage from a waste rock pile, Mine Doyon, Quebec, Canada," Journal of Contaminant Hydrology, vol. 69, no. 1-2, pp. 45-71, 2004.

[18] T. Han, J. Shi, Y. Chen, Z. Li, and W. Ma, "Experimental study of mechanical properties and energy mechanism of calcareous sandstone subjected to water chemistry," Chinese Journal of Rock Mechanics and Engineering, vol. 34, no. S2, pp. 37933804, 2015.

[19] Y. L. Wang, J. X. Tang, J. Jiang, Z. Y. Dai, and G. J. Shu, "Mechanical properties and parameter damage effect of malmstone under chemical corrosion of water-rock interaction," Journal of China Coal Society, vol. 42, no. 1, pp. 227-235, 2017.

[20] X.-T. Feng, S. Chen, and H. Zhou, "Real-time computerized tomography (CT) experiments on sandstone damage evolution during triaxial compression with chemical corrosion," International Journal of Rock Mechanics and Mining Sciences, vol. 41, no. 2, pp. 181-192, 2004.

[21] R. K. Huo, N. Li, and H. D. Liu, "Statistical constitutive model of sandstone subjected to hydrochloric acid attack," Chinese Journal of Rock Mechanics and Engineering, vol. 24, no. 11, pp. 1852-1856, 2005.

[22] R. Huo, T. Qiu, Y. Liang, S. Li, and M. Qian, "The physicomechanical deterioration characteristics and mesoscopic damage analysis of sandstone under acidic environment," Advances in Civil Engineering, vol. 2020, Article ID 7467608, 15 pages, 2020.

[23] S. Li, R. Huo, B. Wang et al., "Experimental study on physicomechanical properties of sandstone under acidic environment," Advances in Civil Engineering, vol. 2018, Article ID 5784831, 15 pages, 2018.

[24] S. Li, R. Huo, F. Yoshiaki, D. Ren, and Z. Song, "Effect of acidtemperature-pressure on the damage characteristics of sandstone," International Journal of Rock Mechanics and Mining Sciences, vol. 122, Article ID 104079, 2019.

[25] H. Wang, Z. Huang, L. Li, Z. You, and Y. Chen, "Three-dimensional modeling and simulation of asphalt concrete mixtures based on X-ray CT microstructure images," Journal of Traffic and Transportation Engineering (English Edition), vol. 1, no. 1, pp. 55-61, 2014.

[26] S.-Q. Yang, Z. Yang, H.-W. Jing, and T. Xu, "Fracture evolution mechanism of hollow sandstone under conventional triaxial compression by X-ray micro-CT observations and three-dimensional numerical simulations," International Journal of Solids and Structures, vol. 190, pp. 156-180, 2020.

[27] G. Wang, J. Shen, S. Liu, C. Jiang, and X. Qin, "Threedimensional modeling and analysis of macro-pore structure of coal using combined X-ray CT imaging and fractal theory," International Journal of Rock Mechanics and Mining Sciences, vol. 123, Article ID 104082, 2019. 
[28] F. Du, K. Wang, X. Dong, and J. Wei, "Numerical simulation of damage and failure of coal-rock combination based on CT three-dimensional reconstruction," Journal of China Coal Society, vol. 1, p. 12, 2021, in Chinese.

[29] S. Chen, Z. Q. Yue, and L. G. Tham, "Digital image based approach for three-dimensional mechanical analysis of heterogeneous rocks," Rock Mechanics and Rock Engineering, vol. 40, no. 2, pp. 145-168, 2007.

[30] W. Sun, K. Hou, Z. Yang, and Y. Wen, "X-ray CT threedimensional reconstruction and discrete element analysis of the cement paste backfill pore structure under uniaxial compression," Construction and Building Materials, vol. 138, pp. 69-78, 2017.

[31] Y. Obara, I. Tanikura, J. Jung, R. Shintani, and S. Watanabe, "Evaluation of micro-damage of concrete specimens under cyclic uniaxial loading by X-ray CT method," Journal of Advanced Concrete Technology, vol. 14, no. 8, pp. 433-443, 2016.

[32] GB/T50266-2013, Standard for Test Methods of Engineering Rock Mass, China Planning Press, Beijing, China, 2013.

[33] K. Winkler and F. Stangenberg, "Numerical analysis of punching shear failure of reinforced concrete slabs," in Proceedings of the 2008 Abaqus Users' Conference, Newport, RI, USA, May 2008.

[34] S.-J. Lee and S. O. Choi, "A study on theoretical consideration and numerical analysis according to dip angle of joint for volumetric expansion ratio of rock mass," Geosystem Engineering, vol. 14, no. 1, pp. 1-8, 2011.

[35] D. Unteregger, B. Fuchs, and G. Hofstetter, "A damage plasticity model for different types of intact rock," International Journal of Rock Mechanics and Mining Sciences, vol. 80, pp. 402-411, 2015.

[36] J. S. Kalyana Rama, D. R. Chauhan, M. V. N. Sivakumar, A. Vasan, and A. Murthy, "Fracture properties of concrete using damaged plasticity model-A parametric study," Structural Engineering and Mechanics, vol. 64, no. 1, pp. 59-69, 2017.

[37] J. Lee and G. L. Fenves, "Plastic-damage model for cyclic loading of concrete structures," Journal of Engineering $\mathrm{Me}$ chanics, vol. 124, no. 8, pp. 892-900, 1998.

[38] J. Lubliner, J. Oliver, S. Oller, and E. Oñate, "A plastic-damage model for concrete," International Journal of Solids and Structures, vol. 25, no. 3, pp. 299-326, 1989.

[39] Hibbitt, Karlsson and Sorensen, ABAQUS: Theory Manual, Hibbitt, Karlsson and Sorensen, Pawtucket, RI, USA, 1997.

[40] J. S. Sun, M. Chen, Q. Jiang, C. Zhou, and W. Lu, "Numerical simulation of mesomechanical characteristics of creep demage evolution for Jingping marble," Rock and Soil Mechanics, vol. 34, no. 12, pp. 3601-3608, 2013. 